\title{
Laparoscopic versus open appendectomy
}

\section{for the treatment of acute appendicitis.}

\author{
RK Mishra, GB Hanna, A Cuschieri \\ Surgical skills Unit: Department of Surgery and Molecular oncology, \\ Ninewells Hospital and Medical School, University of Dundee.
}

\begin{abstract}
::
Open appendectomy is the 'gold standard' for the treatment of acute appendicitis. Laparoscopic appendectomy though widely practiced has not gained universal approval. Although it is a generally safe operation, postoperative complications occur in few patients. Laparoscopic appendectomy was first described in 1983. Reports of early studies were equivocal with few studies evaluating analgesic requirements and the length of hospital stay. This study was aimed to compare laparoscopic with open appendectomy and ascertain the therapeutic benefit, if any, in the overall management of acute appendicitis.
\end{abstract}

\section{Key words:}

Laparoscopic appendectomy, Appendectomy, Appendicitis, Laparoscopic vs. open appendectomy

\section{Introduction:}

Appendicitis was first recognised as a disease entity in the sixteenth century and was called perityphlitis. McBurney described the clinical findings in 1889. Minimal access surgery has been proved to be a useful surgical technique. New standards have been established for various indications. Patient comfort is a greater consideration in the $21^{\text {st }}$ century. The acquisition of recent technology and skills now affords a better choice of the mode of surgery. This document reviews the recent advances in treatment technique applicable to laparoscopic appendectomy, examines the literature, and suggests guidelines for laparoscopic intervention in patients with acute appendicitis.

\section{Aims:}


The aim of this study was to compare the effectiveness and safety of laparoscopic and conventional "open" appendectomy in the treatment of acute appendicitis. The following parameters were evaluated for both laparoscopic and open procedures.

1. Method of patient selection

2. Operative technique

3. Operating time.

4. Intra-operative and postoperative complications.

5. Postoperative pain and amount of narcotic used.

6. Time until resumption of diet.

7. Postoperative morbidity.

8. Hospital stay.

9. Cost effectiveness and

10. Quality of life analyses

\section{Materials and Methods:}

A literature search was performed using Medline and the search engine Google. The following search terms were used: "laparoscopic appendectomy", "appendicitis", and "appendicectomy". 3400 citations found in total. Selected papers were screened for further references. Criteria for selection of literature were the number of cases (excluded if less than 20), methods of analysis (statistical or non statistical), operative procedure (only universally accepted procedures were selected) and the Institution where the study was done (Specialized institution for laparoscopic surgery).

\section{Content:}

\section{Evolution of laparoscopic appendicectomy}


Laparoscopic appendectomy is being done at a time when laparoscopic cholecystectomy has shown definite benefits over the open technique. In the young female the cause of lower abdominal pain is often gynaecological. Gynaecologists perform diagnostic laparoscopy frequently. Semm, a German gynaecologist, performed the first laparoscopic appendectomy in 1983.

Laparoscopic cholecystectomy is now the gold standard for cholelithiasis and has virtually replaced open cholecystectomy. However, is this the case for acute appendicitis? The role of laparoscopic appendectomy has not yet been clearly defined. Laparoscopic surgery continues to evolve at such a rapid pace that it is now time to examine the latest developments with regard to acute appendicitis. Numerous factors need to be considered in deciding the ideal, and most appropriate surgical technique for acute appendicitis.

\section{Diagnosis of acute appendicitis and laparoscopic appendectomy.}

The diagnosis of acute appendicitis is mainly clinical. Several methods have been suggested to diminish the diagnostic error that occurs if diagnosis is based solely on the clinical picture of suspected appendicitis. The symptoms of appendicitis can initially be difficult to differentiate from gastroenteritis. Early symptoms may include vague bloating, indigestion and mild pain which generally is perceived as being in the area of the umbilicus.

As the infection worsens, the pain becomes more prominent in the right lower quadrant. There is usually nausea, vomiting and loss of appetite. The pain is generally constant and progressive. There may be diarrhoea, fever, and chills. These symptoms progress over several hours to several days. However, many patients may not report the sequence of symptoms outlined above. Therefore, an accurate diagnosis of appendicitis can often be challenging. Many other conditions can mimic appendicitis such as gastroenteritis, kidney stones, urinary infections, ulcerative colitis and Crohn's disease. In women, problems such as ovarian cysts and pelvic infections can mimic appendicitis. In fact appendicitis is a disease which can mimic most of the causes of abdominal pain as well as some chest pathology .

Despite new X-ray techniques, CT scans and ultrasounds, the diagnosis of appendicitis can be challenging. So far the most accurate non-invasive method of diagnosis is ultrasonography but this is not totally reliable. The history and physical examination will generally lead to the correct 
diagnosis. According to one prospective non-randomised study laparoscopy may prevent unnecessary appendectomy in $24 \%$ of patients. Laparoscopy reveals a misdiagnosis rate of $8 \%$ in male, and $41 \%$ in female of reproductive age group. [54, 55]. Laparoscopic appendectomy gives a better evaluation of the peritoneal cavity than that obtained by the standard grid-iron exposure. The procedure allows rapid and thorough inspection of the para-colic gutters and the pelvic cavity that is not possible with the open grid-iron approach. The laparoscopic approach for patient with suspected appendicitis improves the diagnostic accuracy and is therefore recommended. [70].

There is also debate on whether a normal looking appendix be removed at the time of laparoscopy or not? The major criticism against leaving the appendix in place is that mucosal inflammation might be overlooked because only serosa can be inspected. Walker et al. reported that $3.2 \%$ of the intra-operatively normal appearing appendices demonstrated acute inflammation after pathological examination [51]. Mucosal inflammation obviously can never be determined if the appendix is left in place. The majority of surgeons state that normal looking appendix should not be removed. [52]. Previously there was doubt on the colour reliability of the image of inflamed appendix on the monitor, but after the advent of the three chip camera the sensitivity of laparoscopic diagnosis of appendix is $92 \%$ [53].

\section{Laparoscopic appendectomy women vs. men}

Most surgeons agree on the use of laparoscopy when a patient is a young female with vague lower abdominal pain and its progress to appendectomy. There are innumerable reports showing that laparoscopy improves diagnosis and reduces unnecessary appendectomies in fertile women $[29,30,41,50,63,65$ and 70$]$.

The diagnostic problem of suspected appendicitis is not limited to fertile women. It is also a problem of premenopausal women. One study was done in Dublin on 100 premenopausal women who were admitted with abdominal pain. After final assessment, patients were placed in following diagnostic categories; gynaecological (30\%); renal (9\%); acute appendicitis (23\%); non specific abdominal pain (29\%) and miscellaneous (9\%).

The mean duration of hospital stay for patient with non specific abdominal pain was 67 days and one third of these patients, underwent appendectomy for normal appendix. [75]. Abdominal 
pain in premenopausal women is often psychosomatic and the laparoscopic intervention may be considered in these women with non-specific pain abdomen to prevent removal of a normal appendix.

Even though laparoscopic appendectomy has been claimed to reduce postoperative pain, length of hospitalisation, analgesic doses and surgery associated complication, many surgeons do not advocate this procedure on men because they do not find any superiority of laparoscopy over the open procedure [20, 28, 31 and 36]. Cox et al conducted a prospective randomized comparison of open versus laparoscopic appendectomy exclusively in men and they reported that laparoscopic appendectomy in men has significant advantages in terms of more rapid recovery. [60]

\section{Appendectomy in paediatric patients.}

Although laparoscopic appendectomy is gaining popularity, open appendectomy has remained popular with surgeons caring for children. The reasons for this include the increased skill level necessary for paediatric laparoscopic procedures, concerns over increased operating times and costs, and fears that the laparoscopic approach to appendicitis is somehow associated with an increased complication rate.

There is a group of surgeons who are advocating laparoscopic appendectomy in all cases of appendicitis in paediatric patients. In one prospective non randomised trial 500 appendectomies were studied, 362 children underwent open procedure and 138 underwent laparoscopic appendectomy. There was no mortality in either group. Major complications were 3\% in open group but no major complications were seen in the laparoscopic group. Minor complications were $20 \%$ in open and $13 \%$ in laparoscopic appendectomy.[76].

Paya et al published a prospective study of 75 children with perforated appendicitis. Ten underwent laparoscopic appendectomy and the remainder underwent open operation. There were no postoperative abscesses in the laparoscopic group but $2(3.1 \%)$ of 65 patients who had open appendectomies developed postoperative intra-abdominal abscesses. [38].

In a prospective series of children aged 4-12 years, reported from Cairo, 48 underwent open appendectomy and 34 laparoscopic operation, over a 6 month period.. Wound complications were fewer, cosmetic appearance better, and time to return to normal activities quicker ( $7 \mathrm{cf} 12$ 
days) in the laparoscopic group. [59]. Lintula H. et al studied the effect of laparoscopic appendectomy in children between 4-15 yr of age and demonstrated that laparoscopic appendectomy was not associated with any increase risk of intra-operative or long term complications. [32].

\section{Appendectomy in Pregnancy:}

Is laparoscopic appendectomy safe in pregnancy? There has been increased interest in using laparoscopic procedures during pregnancy. A prospective study was done to evaluate the safety and outcome of pregnancy after both open and laparoscopic procedures. 11 pregnant women underwent laparoscopic appendectomy and 11 underwent open appendectomy. Their gestation age ranged from 7 to 34 weeks. The following parameters were analysed:

- Obstetric and gynaecologic risk factors,

- Length of procedure,

- Peri-operative complications,

- Length of stay and outcome of pregnancy.

The study showed that laparoscopic appendectomy is safe in all trimesters of pregnancy. There was no significant difference in the length of operation. (60 vs. $46 \mathrm{~min}$ ). There was no fetal loss or other adverse outcome of pregnancy after laparoscopic appendectomy. The development of the infant was normal in both the group of patients. [33].

While these reports indicate that laparoscopy can be safely performed during pregnancy, some surgeons are suggesting that whenever possible, operative intervention should be deferred until the second trimester when foetal risk is lowest [68]. Pneumoperitoneum enhances lowerextremity venous stasis, which already present in gravid patient. Pregnancy also induces a hypercoagulable state, so pneumatic compression devices must be utilised in pregnant women at the time of appendectomy to prevent thromboembolism.

\section{Appendectomy of obese patients}


In the obese patient laparoscopic appendectomy has shown advantage over the open procedure in a faster postoperative recovery. A group of 106 patients with a body mass index (BMI) > 26.4, representing the upper quintile of 500 prospectively randomized patients, were included in the study. They were randomized to undergo either laparoscopic or open appendectomy. Following parameters were evaluated:

- Operating and anaesthesia times,

- Postoperative pain,

- Complications,

- Hospital stay,

- Functional index (1 week postoperatively),

- $\quad$ Sick leave, and

- Time to full recovery.

The prolonged hospital stay and sick leave noted in overweight patients undergoing open appendectomy was abolished when overweight patients were treated with laparoscopic appendectomy. Laparoscopic procedures are however more prolonged in the obese than in the normally nourished $[13,57]$. There is opinion of some surgeons that laparoscopy is beneficial in obese females and those presenting with appendiceal abscess, who are treated by intravenous antibiotics and percutaneous drainage followed by interval appendectomy. But in their opinion laparoscopic appendectomy is not indicated in all patients presenting with periappendicular abscess [57]

\section{Post operative pain}

It is proved that laparoscopic procedures cause less post-operative pain than their conventional counterparts. In this study none of the literature reviewed found more pain after laparoscopic procedure. The post-operative narcotic use is less after laparoscopic appendectomy. In one study done by Ortega et al; linear analogue pain scores were recorded in 135 patients blinded to the procedure of operation by special dressing and pain score was very less in laparoscopic group 
compared to open. Another interesting observation has been the patient's perception of pain after appendectomy. Those who underwent laparoscopic appendectomy were more vocal of pain although it was of a lower intensity. However, after 48 hours they had a better sense of wellbeing and showed earlier postoperative food intake, ambulation and return to work and sport. This could have arisen from the expectation that laparoscopic procedures are painless or a lower level of endorphins released or the peritoneal injury from the pneumoperitoneum.

\section{Post-operative recovery after appendectomy.}

It has been shown that those patients who underwent successful laparoscopic appendectomy have a better postoperative recovery. The reduced trauma to the abdominal wall is a very significant factor in post-surgical discomfort. The better mobility of the abdominal musculature and the earlier ambulation, reduce the risk of the early post-operative complications of pneumonia and embolism.

A prospective randomised multi centre study was performed to compare the outcome of laparoscopic and open appendicectomy in patients with suspected acute appendicitis by Hellberg A et al. Patients having laparoscopic appendectomy recovered more quickly than their open counterpart, but interestingly there was no significant difference in sick leave than after laparoscopic operation. [19]. An insignificant reduction in sick leave after laparoscopic appendectomy may be due to unawareness of general practitioners about recovery time difference between both the procedures, or patient expectation in terms of time off work..

\section{Laparoscopic appendectomy and wound infection.}

The risk of wound infection is less in laparoscopic appendectomy compared to the open procedure. A meta-analysis of randomised controlled trials has been reported with outcomes of 2877 patients included in 28 trials. Overall complication rates were comparable, but wound infections were definitely reduced after laparoscopy $(2.3 \%$ to $6.1 \%)$ [17]. Rohr et al reported higher wound infection rates after laparoscopic appendectomy, but most of the literature supports the view that wound infection is less common after a laparoscopic procedure. It should be cautioned that the definition of wound infection varies between studies.

\section{Laparoscopic appendectomy and intra abdominal abscess:}


Some studies have shown a significantly increased incidence of postoperative intra abdominal abscess with perforated appendicitis after laparoscopic appendectomy $[9,11,27,45,15$, and 47].

More reports show that there is no increased incidence of intra-abdominal abscess formation after laparoscopic appendectomy. Barkhausen S et al conducted one trial, in which 930 patients were analysed retrospectively. Conventional appendectomy was performed in 330 patients; laparoscopic in 554 others. The analysis shows that the incidence of intra abdominal abscess formation rate was same in both groups[8].

In Los Angeles, 2497 appendectomies were reviewed retrospectively. Indications for these procedures included acute appendicitis 57\%, gangrenous appendicitis 12\%, and perforated appendicitis in $31 \%$. There was no difference in the rate of intra-abdominal abscess formation between the groups undergoing open and laparoscopic appendectomies for acute and gangrenous appendicitis. For perforated appendicitis, however, there was significantly higher rate of abscess formation following laparoscopic appendectomy compared to open appendectomy (9.0\% vs. $2.6 \%, \mathrm{P}=0.015 \%)$. [69]

\section{Laparoscopic appendectomy in complicated appendicitis.}

Due to the risk of intra-abdominal abscess formation there is a strong controversy among surgeons regarding the use of the laparoscopic procedure in complicated appendicitis (gangrenous or perforated).

There are several reports which state that if gangrene or perforation is found at the time of laparoscopic appendectomy than the procedure should be converted. Frazee and Bohannon published a retrospective analysis of 15 patients with gangrenous appendicitis and 19 patients with perforated appendicitis who underwent laparoscopic appendectomy. They found a $7 \%$ rate of postoperative intra-abdominal abscess in the gangrenous group and a $26 \%$ rate of postoperative intra-abdominal abscess in the perforated group. [15].

A prospective randomised study by Bonnani et al found that among adult patients, 2 of 66 (3.03\%) patients undergoing open appendectomy for complicated (gangrenous or perforated) appendicitis developed post-operative pelvic abscesses. Three of 11 patients (27\%), developed 
postoperative pelvic abscesses following laparoscopic appendectomy for complicated appendicitis, and 1 patient developed a postoperative hepatic abscess. [9]

Tang et al found a postoperative intra-abdominal abscess rate of $11 \%$ for perforated appendicitis treated laparoscopically compared with a rate of $3 \%$ treated by the open method. [47]

In contrast, there is a group of laparoscopic surgeons, who are now gaining confidence in handling complicated cases of appendicitis. Johnson, after a retrospective trial of 112 patients, advocates that most cases of acute appendicitis with suspected perforation could be managed laparoscopically. There is a large group of surgeons who believe that laparoscopic appendectomy is safe in all form of appendicitis, even in perforated appendicitis $[8,23,24,40$, 66, and 67]. Some believe that even if the patient presents with fresh lower abdominal early peritonitis or even if there is chance of fresh abscess formation, laparoscopic appendectomy is not only justifiable but also even recommended as the procedure of choice [48]. In generalised peritonitis laparoscopic is not advocated.

\section{Operating time and laparoscopic appendectomy.}

In almost all the literature the operating time of laparoscopic appendectomy was found to be more than that of open appendectomy. The difference in mean operating time ranged from 8.3 to 29 minute. The operating time of laparoscopic appendectomy also depends on the experience of the surgeon and the competence of their team. [10].

In considering operating time, the exact identification of the timing of the start of the procedure and its conclusion vary. In general the time should be calculated from the insertion of first trocar to the end of skin suturing. Cox et al. defined operating time as the time from incision to wound closure. [60]. Tate et al calculated the time as use of anaesthesia to the administration of a reversal agent [71]. Generally all laparoscopic procedures are more time consuming for the following reasons.

- Inherent nature of slow manoeuvre of laparoscopic techniques

- Time taken by careful slow insufflation.

- Routine diagnostic laparoscopy before starting any laparoscopic procedure. 
A meta-analysis of randomised controlled trial has been reported with outcomes for 2877 patients. The mean operating time was 16 minutes longer for laparoscopic appendectomy.

A prospective randomized trial comparing laparoscopic appendectomy with open appendectomy was conducted in 158 patients by Hansen et al. They reported that despite of longer operating time, (63 versus 40 minutes) the advantages of laparoscopy (such as fewer wound infection and earlier return to normal activity) make it a worthwhile alternative for patients with a clinical diagnosis of acute appendicitis. [61,60].

Kazemier et al in their report of a randomized clinical trial of 201 patients found that laparoscopic appendectomy is superior to open surgery regarding post operative pain, and, post operative complications, recovery time, and financial [66].

\section{Long term complications and laparoscopic appendectomy:}

Adhesion formation is now one of the most common causes of intestinal obstruction. The role of adhesion in the development of chronic abdominal pain, although less certain, cannot be ignored [1]. Reduced adhesion formation is a substantive long term advantage of laparoscopic appendectomy.

A study reported an adhesion rate of $80 \%$ after open appendectomy compared to $10 \%$ after laparoscopic appendectomy, when patients were laparoscoped three months after surgery.[1] It has been shown that the tissue trauma of the incision increases the total inflammatory response, thereby inhibiting fibrinolysis and promoting fibroblast migration and collagen formation.

These results strongly suggest that laparoscopic surgical techniques lead to fewer intraabdominal adhesions by reducing tissue trauma, which in turn reduces circulating inflammatory mediators. [56]. 


\section{Laparoscopic Appendectomy in some diseased conditions:}

There are some diseases where laparoscopic appendectomy has found clear benefit over open appendectomy.

Cirrhosis

The immunity of the cirrhotic patient is compromised and there is more chance of wound infection with the open procedure. Patients with cirrhosis have shown a faster recovery when treated by laparoscopic procedure, for acute appendicitis [48]. These patients were benefited by this less traumatic method of surgery.

Sickle cell disease

There is also a report that laparoscopic appendectomy has clear benefit over open in-patients with sickle disease. Patients with acute appendicitis will certainly require surgery that may be associated with high morbidity and mortality as a result of peri-operative and postoperative complications, mainly vaso-occlusive crises (VOC). The introduction of minimally access surgery is believed to be associated with minimal risks to the patients due to its numerous advantages over conventional methods.[5]. The morbidity associated with surgery in sickle cell patients can be further reduced by the use of preoperative exchange transfusion and adequate maintenance of hydration in the patient with sickle cell disease

\section{Laparoscopy and Immunity.}

All surgery and anaesthesia can cause depression of cell-mediated immunity in the postoperative period, including reduction in the number of circulating lymphocytes, impairment of natural killer cell cytotoxicity, depression of T cell proliferation, and diminished neutrophil function. Animal and clinical studies have shown that laparoscopic surgery impairs a patient's immune state less than open surgery. Cell-mediated immunity is less impaired after laparoscopic operation than after open. Interleukin 6 levels were less in a study on newborn infants undergoing laparoscopic procedures when compared to open. [55].

\section{Laparoscopy and risk of anaesthesia:}


The general anaesthesia and the pneumoperitoneum required as part of the laparoscopic procedure does increase risk in certain patient groups. Most surgeons would not recommend laparoscopic appendicectomy in;

- Patients with cardiac diseases and COPD

- Should not be considered a good candidate for laparoscopic appendectomy.

- in patients who have had previous lower abdominal surgery

- Laparoscopic appendectomy may also be more difficult

- $\quad$ The elderly

- May also be at increased risk for complications with general anaesthesia combined with pneumoperitoneum.

- Those with lowered cardio-pulmonary reserve

$\circ$ With regard to the consequences of the pneumoperitoneum and a longer operative time.

\section{Cost effectiveness of laparoscopic appendectomy:}

Debate still exists about the cost comparison between laparoscopic and open surgery. Most surgeons have the opinion that laparoscopic appendectomy is cost effective. It may be more expensive for the hospital but it offers diagnostic accuracy, and among employed patients, offers cost savings to society as a result of faster return to work [2, 14, 18, and 64].

Heikkinen TJ et al reported a randomised study for cost effectiveness of laparoscopic appendectomy, the hospital cost for laparoscopic appendectomy was higher, but it offers significant cost savings from the rapid convalescence. Return to normal life and work was faster in the laparoscopic group (14 versus 26.5 days). [18]. The Hospital costs of laparoscopic appendectomy were higher but the total costs were lower, such that a saving of \$1481 was realized by laparoscopic appendectomy. [2] 


\section{Laparoscopic appendectomy and surgical experience}

The outcome of any laparoscopic procedure greatly depends on the experience of the surgeon. In a study of two groups, conducted at Los Angeles, general surgical services operated on 413 patients, and 232 cases underwent the same procedure by trained specialised laparoscopic surgeons.

\begin{tabular}{|l|l|l|l|}
\hline General surgical Services & 285 acute & 61 gangrenous & 67 perforated \\
\hline Laparoscopic surgeons & 126 acute & 46 gangrenous & 60 perforated \\
\hline
\end{tabular}

10 abscesses occurred post operatively $(2.4 \%)$ in the group of patients whose operation was done by general surgical services, and only one case of intra-abdominal abscess $(0.025 \%)$ were reported in the group of patients whose operation were performed by a standardized laparoscopic method, using skilled dissection, careful use of retrieval bag, proper ligation of stump and thorough peritoneal toilet). This study may be taken to indicate that complications such as intraabdominal abscess following laparoscopic appendectomy for perforated appendices can be reduced significantly by training.

\section{Discussion:}

Laparoscopic appendectomy has gained lot of attention around the world. However, the role of laparoscopy for appendectomy, one of the commonest indications, remains controversial. Several controlled trials have been conducted, some are in favour of laparoscopy, others not. The goal of this review was to ascertain that if the laparoscopic appendectomy is superior to conventional, and if so what are the benefits and how it could it be instituted more widely. There is also diversity in the quality of the randomized controlled trials. The main variable in these trials are following parameters:

- Number of patients in trial

- Withdrawal of cases

- Exclusion of cases

- $\quad$ Blinding 
- Intention to treat analysis

- Publication biases

- Local practice variation

- Prophylaxis antibiotic used

- Follow-up failure.

Without proper attention to the detail of all the parameters it is very difficult to draw a conclusion. It has been found among the surgeons that; there is a hidden competition between laparoscopic surgeons and the surgeons who are still doing conventional surgery, and this competition influences the result of study. One should always think of laparoscopic surgery and open as being complimentary to each other.

A successful outcome requires greater skills from the operator. The result of many comparative studies have shown that outcome of laparoscopic appendectomy was influenced by the experience and technique of the operator. Minimal access surgery requires different skills and technological knowledge. With a clear diagnosis of complicated appendicitis, the skill and experience of the surgeon should be considered for the selection of operating method. Surgeons should perform the procedure with which they are more comfortable.

\section{Relative risk factors of laparoscopic appendectomy:}

\section{Missed Diagnosis}

There is report also of Mucinous cystadenoma of the cecum missed at laparoscopic appendectomy. [49]. Less than $1 \%$ of all patients with suspected acute appendicitis are found to have an associated malignant process. During conventional appendectomy through a laparotomy incision, the caecum and the appendix are easily palpated, and an obvious mass can be detected and properly managed at the time of appendectomy. The inability to palpate any mass is an inherent problem of laparoscopic surgery.

\section{Bleeding:}


From the mesoappendix, omental vessels or retroperitoneum. Bleeding is usually recognized intraoperatively via adequate exposure, lighting, and suction. It is recognized post-operatively by tachycardia, hypotension, decreased urine output, anaemia, or other evidence of hemorrhagic shock.

\section{Visceral Injury:}

Risk of accidental burns is higher with monopolar system because electricity seeks the path of least resistance, which may be adjacent bowel. In a bipolar system since the current does not have to travel through the patient, there is little chance of injury to remote viscera. In laparoscopic appendectomy only bipolar current should be used. Laparoscopists should also routinely explore the rest of the abdomen.

\section{Wound infection:}

It is recognised by erythema, fluctuation and purulent drainage from port sites. The absence of wound infections after laparoscopic appendectomy can be attributed to the practice of placing the appendix in a sterile bag or into the trocar sleeve prior to removal from the abdomen. The regular use of retrieval bag is a very good practice for preventing infection of the wound.

\section{Incomplete appendectomy:}

If surgeon is not experienced, the stump of the appendix may be to long. There is a report of intra-abdominal abscess formation due to retained faecolith after laparoscopic appendectomy. It is strongly advised that the surgeons performing laparoscopic appendectomy should remove faecolith if found, and the stump of appendix should not big enough to contain any thing [11]. Incomplete appendectomy is a result of ligation of the appendix too far from the base. It may lead to recurrent appendicitis, which presents with symptoms and signs of appendicitis even after laparoscopic appendectomy.

Some surgeons prefer stapling of the appendiceal stump for laparoscopic appendectomy for the treatment of all forms of appendicitis. [34]. But most of the surgeons now agree that ligation of the appendectomy stump is the best approach. There is report of slippage of clip, residual appendicitis followed by abscess formation after using clip for appendiceal stump. [74]. The ligation should be preformed by using endoloop, an intra-corporeal surgeon's knot, or done extra 
corporeally using a Meltzer's knot or Tayside knot. The security of the knot is essential. It is influenced by the proper port location and experience of the surgeon. [4].

\section{Leakage of purulent exudates from appendix at the time of operation:}

Usually seen intra-operatively while dissecting appendix. Copious irrigation and suction followed by continued antibiotics can prevent this complication until patient is afebrile with a normal white blood cell count. Use a retrieval bag. to prevent the spillage of infected material from the appendiceal lumen.

\section{Intraabdominal abscess:}

This post-operative morbidity is recognised by prolonged ileus, sluggish recovery, rising leukocytosis, spiking fevers, tachycardia, and rarely a palpable mass. After confirmation of the intra-abdominal abscess drainage of pus followed by antibiotic therapy is essential. Sometime laparotomy may be required.

\section{Hernia:}

Trocar site hernia as visible or palpable bulge is sometime encountered. Possible occult hernia manifested by pain or symptoms of bowel obstruction.

Laparoscopic appendectomy is now safe in experienced hands. In experienced hands, satisfactory peritoneal toilet can be performed even in the presence of Peri-appendiceal pus and regional peritonitis. Laparoscopic appendectomy is not advocated when the patient has generalised peritonitis.

Indications for the surgical treatment of appendicitis

\begin{tabular}{|l|l|}
\hline \multicolumn{1}{|c|}{ Laparoscopic appendectomy } & \multicolumn{1}{c|}{ Open appendectomy } \\
\hline Female of reproductive age group & Complicated appendicitis \\
\hline Female of pre-menopausal group & COPD or Cardiac disease \\
\hline Suspected appendicitis & Generalised peritonitis \\
\hline High working class & Previous lower abdominal surgery \\
\hline Obese patients & Hypercoagulable sates \\
\hline
\end{tabular}




\begin{tabular}{|l|l|}
$\begin{array}{l}\text { Disease conditions like Cirrhosis of liver } \\
\text { and sickle cell disease }\end{array}$ & $\begin{array}{l}\text { Stump appendicitis after previous } \\
\text { Incomplete appendectomy }\end{array}$ \\
\hline Immune-compromised patients & \\
\hline
\end{tabular}

\section{Future prospects of laparoscopic appendectomy.}

In the future, remote handling technology will overcome some of the manipulative restriction of current instruments. There is no doubt that 20 years from now some surgeons will be operating exclusively via a computer interface controlling a master-slave manipulator. But the future of any new technology depends upon applications and training. [3].

\section{Conclusion:}

Laparoscopic appendectomy is equally safe, and can provide less postoperative morbidity in experienced hands, as open appendectomy. Most cases of acute appendicitis can be treated laparoscopically. Laparoscopic appendectomy is a useful method for reducing hospital stay, complications and return to normal activity. With better training in minimal access surgery now available, the time has arrived for it to take its place in the surgeon's repertoire.

\section{References:}

[1] Cuschieri. A. Appendectomy-laparoscopic or open? Surg Endosc (1997) 11: 319-320.

[2] Cuschieri. A. Cost efficacy of laparoscopic vs. open surgery. Surg Endosc (1998) 12: 11971198.

[3] Cuschieri. A. The dawn of a new century. Surg Endosc (2000) 14: 1-4.

[4] Cuschieri. A. Optimal port locations for endoscopic intracorporeal knotting. Surg Endosc (1997) 11: 397-401.

[5] Alaud-Din AH, Hussein AE, Haddad M. Laparoscopic cholecystectomy and appendectomy with sickle cell disease. Surgi Laparosc Endosc 1998 Oct; 8(5): 380-3

[6] Anderson DG, Edelman DS, Laparoscopic appendectomy versus open appendectomy: a single institution study. J Soc Laparoendosc Surg 1997 Oct-Dec; 1(4): 323-4 
[7] Attwood SEA, Hill ADK, Murphy PG, Thornton J, Stephens RB. A prospective randomised trial of laparoscopic versus open appendectomy. Surgery. 1992; 219:725-731.

[8] Barkhausen S, Wullstein C, Gross E. Laparoscopic versus Conventional appendectomy-a comparision with reference to early Post operative complications. Zentaralbl Chir 1998; 123(7): 85862.

[9] Bonanni F, Reed J III, Hartzell G, et al. Laparoscopic versus conventional appendectomy. J Am Coll Surg; 1994; 179:273-278.

[10] Chung RS, Rowland DY, Li P, Diaz J. A meta-analysis of randomised controlled trials of laparoscopic versus conventional appendectomy. Am J Surg 1999 Mar; 177(3): 250-6.

[11] D. W. Strathern, B. T. Jones. Retained fecolith after laparoscopic appendectomy. Surg Endosc (1999) 13: 287-289.

[12] E. M. Sozuer, A. Bedirli, M. Keceli, O. Yuksel. Laparoscopic Appendectomy for Acute Appendicitis. Surgical EndoscopyVolume 14, 2000.

[13] Enochsson L; Hellberg A; Rudberg C; Fenyo G; Gudbjartson T; Kullman E; Ringqvist I; Sorensen S; Wenner J. laparoscopic versus open appendectomy in overweight patients. Surg Ensosc 2001 Apr; 15(4): 387-92.

[14] Fallahzadeh H. Should a laparoscopic appendectomy be done? Am Surg 1998 Mar; 64(3): 231-3.

[15] Frazee RC, Bohannon WT. A prospective randomised trial comparing open versus laparoscopic appendectomy. Arch Surg.1996; 131:509-512.

[16] Golub R, Siddiqui F, Pohl D. Laparoscopic versus open appendectomy: a metaanalysis. J Am Coll Surg 1998 May; 186(5): 545-53.

[17] Hansen JB, Smithers BM, Schache D, Wall DR, Miller BJ, Menzies BL. Laparoscopic versus open appendectomy. World J Surg.1996; 20:17-21. 
[18] Heikkinen TJ, Haukipuro K, Hulkko A. Cost-effective appendectomy. Open or laparoscopic? A prospective randomised study. Surg Endosc 1998 Oct; 12(10): 1204-8.

[19] Hellberg A, Rudberg C, Kullman E, Enochsson L, Fenyo G, Graffner H, Hallerback B, Johansson B, Anderberg B, Wenner J, Ringqvist I, Sorensen S. Prospective randomized multicentre study of laparoscopic versus open appendicectomy. Br J Surg 1999 Jan; 86(1): 4853.

[20] Helmy MA. A comparative study between laparoscopic versus open appendectomy in men. J Egypt Soc Parasitol 2001 Aug; 31(2): 555-62.

[21] Huang MT, Wei PL, Wu CC, Lai IR, Chen RJ, Lee WJ. Needlescopic, laparoscopic, and open appendectomy: a comparative study. Surg Laparosc Endosc Percutan Tech 2001 Oct; 11(5): 306-12.

[22] Jefferson P. Casto MD, Anthony J. LaPorta, MD. Laparoscopic appendectomy. SAGES J.2001.

[23] Kang KJ; Lim TJ; Kim YS. Laparoscopic appendectomy is feasible for the complicated appendicitis. Surg Laparosc Endosc Percutan Tech 2000 Dec; 10(6): 364-7.

[24] Kathouda N; Friedlander MH; Grant SW; Achanta KK; Essani R; Paik P; Velmahos G; Campos G; Mason R; Mavor E. Intraabdominal abscess rate after laparoscopic appendectomy. Am J Surj 2000 Dec; 180(6): 456-9.

[25] Kazemier G, de Zeeuw GR, Lange JF, Hop WCJ, Bonjer HJ. Laparoscopic vs. open appendectomy. A randomised clinical trial. Surg Endosc 1997 Apr; 11(4): 336-40.

[26] Klingler A, Henle KP, Beller S, Rechner J, Zerz A, Wetscher GJ, Szinicz G. Laparoscopic appendectomy does not change the incidence of postoperative infectious complications. Am J Surg 1998 Mar, 175(3): 232-5.

[27] Krisher SL; Browne A; Dibbins A: Akacz N; Curci M. intra abdominal abscess after laparoscopic appendectomy for perforated appendicitis. Arch Surg 2001 Apr; 136(4): 438-41. 
[28] Kurtz RJ, Heimann TM. Comparison of open and laparoscopic treatment of acute appendicitis. Am J Surj 2001 Sep; 182(3): 211-4.

[29] Laine S, Rantala A, Gullichsen R, Ovaska J. A comparison of laparoscopic and open appendectomy. Surg Endosc 1997 Feb; 11(2): 95-7.

[30] Larsson PG; Henricsson G; Olsson M; Boris J; Stroberg P; Tronstad SE; Skullman S. laparoscopy reduces unnecessary appenicectomies and improves diagnosis in fertile women. A randomised study. Surg Endosc 2001 Feb; 15(2): 200-2

[31] Lavonius MI, Liesjarvi S, Ovaska J, Pajulo O, Ristkari S, Alanen M. laparoscopic versus open appendectomy in children: a prospective randomised study. Eur J Pediatr Surj 2001 Aug; 11(4): $235-8$.

[32] Lintula H; Kokki H; Vanamo K. Single-blind randomised clinical trial of laparoscopic versus open appendectomy in children. Br J Surg 2001 Apr; 88(4): 510-4.

[33] Lyass S; Pikarsky A; Eisenberg VH; Elchalal U; Schenker JG; Reissman P. Is laparoscopic appendectomy safe in pregnant women? Surg Endosc 2001 Apr; 15(4): 377-9.

[34] M. Wagner, D. Aronsky, J. Tschudi, A. Metzger, C. Klaiber. Laparoscopic stapler appendectomy. Surg Endosc (1996) 10: 895-899.

[35] Martin LC, Puente I, Sosa jl, et al. Open versus laparoscopic appendectomy. Ann surg. $1995 ; 222: 256-262$.

[36] Minne L, Varner D, Burnell A, Ratzer E, Clark J, Haun W. Current techniques in laparoscopic appendectomy. Surg Laparosc Endosc 1993 Dec; 3(6): 470-6.

[37] Nowzaradan Y, Barnes JP Jr. Laparoscopic vs. open appendectomy. Prospective randomised study of outcomes. Arch Surg 1997 Jul; 132(7): 708-11; discussion 712.

[38] Paya K, Rauhofer U, Rebhandl W, Deluggi St, Horcher E. Perforating appendicitis: an indication for laparoscopy? Surg Endosc. 2000; 14:182-184. 
[39] Pederson AG; Peterson OB; Wara P; Rnning H; Qvist N; Laurberg S. Randomised clinical trial of laparoscopic versus open appendectomy. Br J Surg 2001 Feb; 88(2): 200-5.

[40] Piskun G, Kozik D, Rajpal S, Shaftan G, Fogler R. comparison of laparoscopic, open and converted appendectomy for perforated appendicitis. SurgEndosc 2001 Jul; 15(7): 660-2.

[41] Reiertsen O, Trondsen E, Bakka A, Andersen OK, Larsen S, Rosseland AR. Prospective non-randomized study of conventional vs. laparoscopic appendectomy. World J Surg.1994; May-Jun; 18(3): 411-5.

[42] Sauerland S, Lefering R, Holthausen U, Neugebauer EA. Laparoscopic vs. conventional appendectomy — a meta-analysis of randomised controlled trials. Langenbecks Arch Surg 1998 Aug; 383(3-4): 289-95.

[43] Slim K, Pezet D, Chipponi J. Laparoscopic or open appendectomy? Critical review of randomised, controlled trials. Dis Colon Rectum 1998 Mar; 41(3): 398-403.

[44] Sorensen S, et al. Prospective randomised multicenter study of laparoscopic versus open appendectomy. Br J Surg 1999 Jan: 86(1): 48-53.

[45] Stacy L. Krisher, MD; Allen Browne, MD; Albert Dibbins, MD; Nancy Tkacz, PNP; Michael Curci, MD. Intra-abdominal Abscess after Laparoscopic Appendectomy for Perforated Appendicitis. Arch Surg. 2001; 136:438-441.

[46] Stöltzin H; Thon K. Perforated appendicitis is laparoscopic appendectomy advisable? Dig Surg 2001; 17(6): 610-616.

[47] Tang E, Ortega AE, Anthone GJ, Beart RW Jr. Intraabdominal abscesses following laparoscopic and open appendectomies. Surg Endosc.1996; 10:327-328.

[48] Tsugawa K, Koyanagi N, Hashizume M, Tomikawa M, Ayukawa K, Akohoshi K, Sugimachi K. A comparison of an open and laparoscopic appendectomy for patient with liver cirrhosis. Surg Laparosc Endosc Percutan Tech 2001.

[49] V. Shayani. Mucinous cystadenoma of the cecum missed at laparoscopic appendectomy. Surg Endosc (1999) 13: 1236-1237. 
[50] Zaninotto G, Rossi M, Anselmino M, Contantini M, Pianalto S, Baldan N, Pizzato D, Ancona E. Laparoscopic vs. conventional appendectomy for suspected appendicitis in women. Surg Endosc (1995) Mar; 9(3): 337-40.

[51] Walker SJ, West CR, and Colmer MR (1995) acute appendicitis: does removal of a normal appendix matter, what is the value of diagnostic accuracy, and is surgical delay important? Ann R Coll Surg Eng1 77:358-363

[52] A.C.Moberg, A. Montgomery. Introducing diagnostic laparoscopy for patient with suspected acute appendicitis. Surg Endosc (2000) 14: 942-947.

[53] S.H.Teh, S.O’Ceallaigh, J.G.K. McKeon, M.K. O’Donohoe, W.A Tanner and F.B.V.Keane. Eur J Surg 2000; 1666: 388-389.

[54] S.H.A.J. Tytgat, X.R.Bakker, R.M.J.M.Butzelaar. Laparoscopic evaluation of patients with suspected acute appendicitis. Surg Endosc (1998) 12: 918-920.

[54] Anders Thorell, Staffan grondal, Kjell Schedvins and Goran Wallin. Eur J Surg 1999; 165 : $751-754$.

[55] Fujimoto T, Segawa o, Lane G.J., Esaki S, Miyana T. Surg Endosc 1999; 13:773-777.

Interleukin 6 levels were less in a study on newborn infants undergoing laparoscopic procedures when compared to open.

[56] C.L.Garrard, R.H.Clements, L.Nanney, J.M.Daviddson, W.O.Richards.Surg Endosc 1999;

13: 10-13. Adhesion formation is reduced after laparoscopic surgery.

[57] A.H. Mat Sain. Surgical Endoscopy. Online publication: 16 August 2001. Laparoscopic interval appendectomy for periappendicular abscess.

[58] L. Enochsson, A. Hellberg, C. Rudberg, G. Fenyö, T. Gudbjartson, E. Kullman, I. Ringqvist, S. Sörensen, and J. Wenner Surgical Endoscopy. Online publication: 6 February 2001. Laparoscopic vs. open appendectomy in overweight patients.

[59] S.A. Hay. Pediatric Surgery International. Online publication December 9, 1997. Laparoscopic versus Conventional appendectomy in children. 
[60] Michael R. Cox, John L. McCall, James Tooli, Robrt T.A. Padbury, Thomas G. Wilson, David A. Wattchow, Mary Langcake. World J. Surg. 20:263-266 (1996). Prospective Randomised Comparison of open versus Laparoscopic appendectomy in Men.

[61] John Brendan Hansen, Bernard Mark Smithers, David Schache, Daryl Robert Wall, Brian John Miller, Betty Lynette MenZies. World J. Surg. 20; 17-21 (1996).

[62] Abe Fingerhut, Bertrand Millat, Frederic Borrie. World J. Surg. 23:835-845 (1999).

[63] P.J. Borgstein, R.V. Gordijn, Q.A.J. Eijsbouts, M.A. Cuesta. Surg Endosc (1997) 11: 923-927. Acute appendicitis- a clear cut case in men, a guessing game in young women.

[64] T.J. Heikkinen, K. Haukipuro, A. Hulkko. Surg Endosc (1998) 12: 1204-1208. Costeffective appendectomy. Open or laparoscopic a prospective randomized study.

[65] S.Lain, A.Rantala, R. Gullichsen, J. Ovaska. Surg Endosc (1997) Laparoscopic appendectomy- Is it Worthwhile? A prospective, randomized study in young women.

[66] G. Kazemier, G.R.de Zeeuw, J.F. Lange, W.C.J.Hop, H.J. Bonjer. Surg Endosc (1997) 11: 336-340. Laparoscopic VS open appendectomy. A randomized clinical trial.

[67] A.B. Johnson, M.E. Peetz. Surg Endosc (1998). Laparoscopic appendectomy is an acceptable alternative for the treatment of perforated appendicitis.

[68] Amos J.D, Schorr SJ, Norman PF, Poole GV, et al. Am J Surg 435-437. Laparoscopic surgery during pregnancy.

[69] Paik PS et al. Intra-abdominal abscess following laparoscopic appendectomies. J Gastroentest Surg 1997 Mar; 1(2): 188-193

[70] Reierston, O. Larsen S. et al. Randomised controlled trial with sequential design of laparoscopic versus conventional appendectomy. Br J Surg 1997, 84, 842-847.

[71] Tate JJT. Laparoscopic appendectomy. Br J Surg 1996; 83:1169-70. 
[72] Ortega AE, Hunter JG, Peters JH, Swanstrom LL, Schirmer B. A prospective randomised comparison of laparoscopic appendectomy with open appendectomy. Am J Surg 1995; 169: 20813.

[73] Rohr S, Thiry C, de manzini N, Perrauid V, Meyer C. Laparoscopic vs open appendectomy in men: a prospective randimized study. Br J Surg 1994; 81(suppl):6-7.

[74] Milne A.A. Bradbury A.W. Residual appendicitis following incomplete laparoscopic appendectomy. Br Jr Surg 1996, 83,217.

[75] O'Byrne JM, Dempsey CB, O'Malley MK, O'Connell FX. Non-specific abdominal pain in pre-menopausal women. Ir J Med Sci. 1992 Apr; 161(4)126.

[76] Paya K. Fakhari M. Rauhofer U. Felberbauer FX. Rebhandl W. Horcher E. JSLS. J Soc Laparoendosc Surg. 2000:4:121-124.

For more information please log on to http://www.laparoscopyhospital.com 